\title{
Red meat: another inconvenient truth
}

\author{
Fiona Godlee editor in chief
}

The BMJ

Evidence continues to emerge linking high meat consumption with increased mortality. This week Arash Etemadi and colleagues provide further support for the association (doi:10. 1136/bmj.j1957). Their population based cohort study links high intake of red and processed meat with increased deaths from all causes and from nine specific ones.

Dietary epidemiology studies are of course fraught with pitfalls. At their worst they attract ridicule for supporting every conceivable association, fuelling public confusion and fake news. This week's study is large, with more than 7.5 million American person years of observation, and it's well done. Although its main findings are based on a single dietary assessment, a subgroup had two assessments done on separate occasions, and these associations were if anything stronger. Importantly, death rates were lower in groups who ate a higher proportion of fish and poultry than red meat.

In the accompanying commentary John Potter provides no comfort for anyone wanting to deny an inconvenient truth (doi:10.1136/bmj.j2190). "Overconsumption of meat is bad for health and for the health of our planet," he says. It seems our ancestors ate meat at most once a week, consuming 5-10 kg a year. Modern diets in rich countries deliver more than 10 times this amount, with animal protein now providing up to a fifth of our energy requirements. The study suggests that haem iron in red meat and nitrate/nitrite in processed meat are among the culprits. But Potter says that the ill effects are likely to be caused in many different ways, including carcinogens caused by cooking, contaminants in animal feed, and reduced intake of plant based foods.

Nor is earlier death the only concern for human health, he says. A high meat economy brings with it accelerated sexual development and antibiotic resistance, together with shortages of food, and animal to human disease epidemics thrown in for good measure. As for the effects on the planet, water depletion, methane production, and pollution of air and groundwater are just the beginning. We must of course reduce the use of fossil fuels in transport, but livestock production outstrips this as a cause of climate change.

Potter outlines two possible courses of action. "As with many contemporary problems of resource overuse and maldistribution, we need to decide whether to act now to reduce human meat consumption or wait until the decay of sufficient parts of the global system tip us into much poorer planetary, societal, and human health."

What can doctors do? We can lobby for more and better research to support clearer evidence based dietary guidelines. And we can lead by example, as our predecessors did with smoking cessation, by reducing our own red meat consumption. Your own suggestions are welcome. 